\title{
Ionic [Ru] complex with recyclability by electro-adsorption for efficient catalytic transfer hydrogenation of aryl ketones
}

\author{
Chuan-Jun Yue*, Qiu-Neng Xu, Li-Ping Gu, Jin-Fang Wang \\ School of Mathematics and Chemical Engineering, Changzhou Institute of Technology, Department of Chemical Engi- \\ neering, Changzhou 213022, P.R. China \\ "Corresponding author: e-mail: ywangjung@163.com
}

\begin{abstract}
The efficient reuse of homogeneous catalyst is important. Cation complex of $\left[\mathrm{Ru}\left(\eta^{6}-\mathrm{p}\right.\right.$-cymene $)\left(\mathrm{PPh}_{3}\right)\left(\mathrm{CH}_{3} \mathrm{CN}\right)$ $\mathrm{Cl}] \mathrm{PF}_{6}$ with different ligands was synthesized and characterized by infrared spectroscopy (IR), ${ }^{1} \mathrm{H}-,{ }^{13} \mathrm{C}-$ and ${ }^{31} \mathrm{P}-$ nuclear magnetic resonance spectroscopy $\left({ }^{1} \mathrm{H}-,{ }^{13} \mathrm{C}\right.$ - and $\left.{ }^{31} \mathrm{P}-\mathrm{NMR}\right)$, element analysis (EA), and high resolution mass spectrometry (HR-MS). The complex was used as a catalyst for the hydrogen transfer reduction of carbonyl for the first time, presenting an excellent catalytic performance of $89 \%-98 \%$ conversion of acetophenone and its derivatives. The catalyst may be efficiently reused by the electro-adsorption of 10 times to one catalyst recovery. The cation $[\mathrm{Ru}]$ complex presented advantages of both homogeneous and heterogeneous catalysts.
\end{abstract}

Keywords: ionic Ru complex, transfer hydrogenation, electron-adsorption, catalyst recovery.

\section{INTRODUCTION}

Organometallics are widely used as reagents or catalysts in organic synthesis ${ }^{1-3}$. The use of organometallics allows for the cleavage and recombination of various chemical bonds, especially in the catalysis of organic transformation, such as reduction of olefin, carbonyl, and imine $^{4-6}$, the oxidation of alcohol and aldehyde ${ }^{7-8}$, and activation of $\mathrm{C}-\mathrm{H}$ bond and small inert molecule, such as nitrogen ${ }^{9-10}$. However, compared with its outstanding homogeneous catalysis, the catalytic efficiency of heterogenize organometallics decreases, sometimes drastically, through a variety of ways based on the catalyst separation and reuse. So far, the reconcile of the catalytic efficiency for repeated use is very difficult. However, the use of homogeneous catalyst containing noble metal for industrial application is expensive. Although many methods exist for the heterogenization of organometallics ${ }^{11}$, new heterogenization methods continue to emerge, such as nanotechnology ${ }^{12}$, metal organic framework ${ }^{13}$ and magnetic recovery ${ }^{14}$. These heterogenization methods, including the traditional immobilized technology, could be divided into two types: the immobilization by the modification of organometallics, like the connection to inorganic and organic support; and change in the forms of organometallics, like nanometer scale and skeleton structure dimension. In addition, regardless of the type of method, some changes in the electronic and steric properties in organometallics were observed, thus the catalytic performance of organometallics would change to some extent. Therefore, the new method for the heterogenization and the reuse of organometallics catalyst is expected to be created as soon as possible. However, the ionic organometal presented an excellent catalytic performance of carbonyl reduction, coupling reaction and others ${ }^{15-18}$. Ionic $[\mathrm{Ru}]$ arene thioamide complex could efficiently catalyze the transfer hydrogenation of carbonyl to obtain the best yield of $99 \%$ under mild conditions ${ }^{19}$; however the life of the catalyst was not enough, which was necessarily solved for the further industrial application. Fortunately, focusing on the ionic Ru catalysts, you will find the charge in ionic Ru complex, which may aid in the catalytic separation after use. This paper reports a new type of ionic $\mathrm{Ru}$ complex for the transfer hydrogenation of aryl ketones. Furthermore, the separation and reuse of catalyst is tried by electric-adsorption adopting the charge on the catalyst.

\section{EXPERIMENTAL DETAILS}

\section{Material and methods}

Unless otherwise stated, all reagents were deoxidized into nitrogen environment by reflux or vacuum before use. $\mathrm{Ru}\left(\eta^{6}\right.$-p-cymene $) \mathrm{Cl}_{2}$ complex was obtained from Zhejiang Metallurgy Research Institute, $\mathrm{PPh}_{3}, \mathrm{NH}_{4} \mathrm{PF}_{6}$, and acetophenone and its derivatives were purchased from Aladdin Company in Shanghai. The glassy carbon electrode $(45 \mathrm{~mm} \cdot 25 \mathrm{~mm} \cdot 3 \mathrm{~mm})$ which was ordered from the United States, was delivered by Tianjin AID Ahengsheng Science-Technology Development Co., Ltd, Other materials were purchased from local suppliers .

Infrared spectrum (IR) was recorded on a Thermo Fisher IR200 FT-IR spectrometer as a KBr pellet. Nuclear magnetic resonance (NMR) spectra were collected with a Bruker Avance-400 spectrometer in $\mathrm{CDCl}_{3}$. Microanalyses were performed with a Perkin-Elmer 2400 Series-II elemental analyser (EA). HRMS mass spectrometry was conducted on an Agilent (6500 series Q-TOF) mass spectrometer. An INESA UV-723 spectrophotometer with1-mm cells was used for measurements of the absorbance and derivative absorption spectra.

\section{Catalyst preparation and characterization}

The improved preparation of the catalyst was performed through the two steps stated below on the basis of the reported literature $\mathrm{e}^{20-21}$.

Preparation of $\mathrm{RuCl}_{2}\left(\eta^{6}\right.$-p-cymene $)\left(\mathrm{PPh}_{3}\right)$

$\mathrm{Ru}\left(\eta^{6}\right.$-p-cymene $) \mathrm{Cl}_{2}(0.64 \mathrm{mmol})$ and $\mathrm{PPh}_{3}(1.28 \mathrm{mmol})$ were placed into a three-neck flask with $30 \mathrm{~mL}$ of dry methanol under nitrogen atmosphere, and the mixture was heated to reflux with stirring for $24 \mathrm{~h}$. After cooling, solid precipitation was formed, subsequently, the reddish brown powder was obtained by the filtration and drying in vacuum, and the yield was $84 \%$. FT-IR $\left(\mathrm{KBr}, \mathrm{cm}^{-1}\right)$ : 3098, 3046, 2972, 2933, 2880, 1425, 746; ${ }^{1} \mathrm{H}$ 
$\operatorname{NMR}\left(\mathrm{CDCl}_{3}\right): \delta 7.84-7.25(\mathrm{~m}, 15 \mathrm{H}), 5.18(\mathrm{~d}, 2 \mathrm{H}), 4.98$ (d, 2H), 2.85 (sept, 1H),1.85 (s, 3H), 1.07 (d, 6H); ${ }^{13} \mathrm{C}$ NMR $\left(\mathrm{CDCl}_{3}\right): \delta 134.4\left(\mathrm{~d}, \mathrm{PPh}_{3}\right), 128.0\left(\mathrm{~s}, \mathrm{PPh}_{3}\right), 128.2$ (d, $\mathrm{PPh}_{3}$ ), 111.3 (s, p-cymene), 96.1 (s, p-cymene), 89.2 (s, p-cymene), 87.2 (s, p-cymene), 30.3 (s, p-cymene), 22.0 (s, p-cymene),17.7 (s, p-cymene); ${ }^{31} \mathrm{PNMR}\left(\mathrm{CDCl}_{3}\right)$ : $\delta \mathrm{d}$ $23.2\left(\mathrm{~s}, \mathrm{PPh}_{3}\right)$; ESI-MS: m/z $568[\mathrm{M}]^{+}$; Anal. Calcd for $\mathrm{C}_{28} \mathrm{H}_{29} \mathrm{Cl}_{2} \mathrm{PRu}$ (MW $568.48 \mathrm{~g} / \mathrm{mol}$ ): C, 59.15; H, 5.14. Found: C, 59.23; H, 5.21.

Preparation of $\left[\mathrm{Ru}\left(\eta^{6}\right.\right.$-p-cymene $\left.)\left(\mathrm{PPh}_{3}\right)\left(\mathrm{CH}_{3} \mathrm{CN}\right) \mathrm{Cl}\right] \mathrm{PF}_{6}$ (ionic [Ru])

$\mathrm{RuCl}_{2}\left(\mathrm{PPh}_{3}\right)\left(\eta^{6}\right.$-p-cymene $)(0.57 \mathrm{mmol})$ and $\left[\mathrm{NH}_{4}\right] \mathrm{PF}_{6}$ $(0.75 \mathrm{mmol})$ were placed into a three-neck flask with 30 $\mathrm{mL}$ of dry $\mathrm{CH}_{3} \mathrm{CN}$ under nitrogen atmosphere, and the mixture was heated to reflux with stirring for $0.5 \mathrm{~h}$. After cooling, the solvent was removed under reduced pressure. The oily precipitation produced after the dry $\mathrm{CH}_{2} \mathrm{Cl}_{2}$ extraction and hexane addition, and the wet solid was obtained after the supernatant was removed by suction and the solvent was removed by pumping. Finally, the yellow powder with a yield of $86 \%$ was collected after the remainder was washed with ether and dried in vacuum. m.p. $>165^{\circ} \mathrm{C}$ (decomp.). FT-IR $\left(\mathrm{KBr}, \mathrm{cm}^{-1}\right)$ : 3096, 3044, 2971, 2931, 2878, 1585, 1424, 842, 745; ${ }^{1} \mathrm{H} \mathrm{NMR}\left(\mathrm{CDCl}_{3}\right)$ : 87.41-7.80 (m, 15H), $6.12(\mathrm{~d}, 1 \mathrm{H}), 5.95(\mathrm{~d}, 1 \mathrm{H}), 5.41$ (d, 1H), 4.67 (d,1H), 3.06 (sept, 1H), 1.94 (s, 3H), 1.75 (s, $3 \mathrm{H}), 1.36(\mathrm{~d}, 3 \mathrm{H}), 1.34(\mathrm{~d}, 3 \mathrm{H}) ;{ }^{13} \mathrm{CNMR}\left(\mathrm{CDCl}_{3}\right)$ : $\delta 134.6$ $\left(\mathrm{d}, \mathrm{PPh}_{3}\right), 131.5\left(\mathrm{~d}, \mathrm{PPh}_{3}\right), 130.1\left(\mathrm{~d}, \mathrm{PPh}_{3}\right), 128.6(\mathrm{~d}$, $\mathrm{PPh}_{3}$ ), 127.6 (s, $\mathrm{CH}_{3} \mathrm{CN}$ ), 116.5 (d, p-cymene),103.5 (s, p-cymene), 95.7 (d, p-cymene), 89.8 (s, p-cymene), 89.3 (br, p-cymene), 85.1 (br, p-cymene), 31.3 (s, p-cymene), 23.8 (s, p-cymene), 21.3 (s, p-cymene), 18.4 (s, p-cymene), 3.3 (s, p-cymene). ${ }^{31} \mathrm{PNMR}\left(\mathrm{CDCl}_{3}\right): \delta 35.8\left(\mathrm{~s}, \mathrm{Ru} \mathrm{PPh} \mathrm{Ph}_{3}\right)$, -144.4 (sept, PF6). HRMS $\left(\mathrm{CH}_{2} \mathrm{Cl}_{2}\right): \mathrm{m} / z, 533(55 \%)$ $\left[\mathrm{M}-\mathrm{CH}_{3} \mathrm{CN}\right]^{+}, 574[\mathrm{M}]^{+}, m / z, 145\left[\mathrm{PF}_{6}\right]^{-}$. Anal. Calcd for $\mathrm{C}_{30} \mathrm{H}_{32} \mathrm{ClF}_{6} \mathrm{NP}_{2} \mathrm{Ru}(719.05 \mathrm{~g} / \mathrm{mol}): \mathrm{C}, 50.11 ; \mathrm{H}, 4.49 ; \mathrm{N}$, 1.95. Found: C, 50.22; H, 4.50; N, 1.96 .

\section{Procedure for catalytic transfer hydrogenation}

The typical process for the catalytic transfer hydrogenation of acetophenone is as follows: $25 \mathrm{~mL}$ of dry isopropanol and $5.2 \mathrm{mmol}$ of dry acetophenone were poured into a three-neck flask under nitrogen atmosphere, and $2.6 \times 10^{-5} \mathrm{~mol}$ of $\left[\mathrm{RuCl}\left(\eta^{6}\right.\right.$-p-cymene $)\left(\mathrm{CH}_{3} \mathrm{CN}\right)$ $\left(\mathrm{PPh}_{3}\right) \mathrm{PF}_{6}$ and $5.2 \times 10^{-4} \mathrm{~mol} \mathrm{KOH}$ were introduced with stirring. Then, the mixture was heated under the desired temperature. The reaction time was determined by TLC (silica gel plate, developing agent $V_{\text {mineral ether }}$ $\left.V_{\text {acetic ether }}=8 / 1\right)$.

After cooling, the reacted liquid was filtered into the special three-neck flasks with the caliber size of $30 \mathrm{~mm}$ of both sides and $19 \mathrm{~mm}$ of middle under nitrogen atmosphere, and a pair of panel glassy carbon electrode was placed into the flask (Fig. 1). The improved procedure of the catalyst recovery was as follows based on the reported description ${ }^{22}$. Under a stream of nitrogen, the panelelectrode was electrified under a voltage of $1.0 \mathrm{~V}$ for $5 \mathrm{~min}$ and the power was cut off. Then the electrode was taken out and immediately immersed into another flask using a similar procedure as above with an equal reaction liquid without catalyst, and instantaneously reverse current was put through to take off the adsorbed

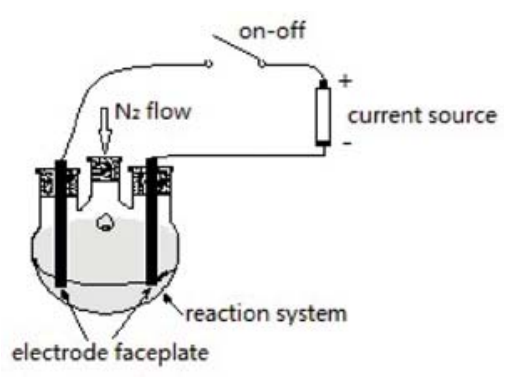

Figure 1. Device for catalyst recovery by electric-adsorption

catalyst into the reaction liquid. A sample of the residual liquid was taken for determining the concentration of $\mathrm{Ru}$ complex by the atomic absorption spectra using external standard method ${ }^{23}$. The adsorption-desorption process was repeated 10 times. The remaining liquid was subjected to GC analysis (PEG-20M capillary column, FID detector, $185^{\circ} \mathrm{C}$ column temperature), and the collected catalyst was tested for the repeated catalytic performance of transfer hydrogenation of acetophenone.

\section{RESULTS AND DISCUSSION}

\section{Catalyst analysis}

Ionic organometallics with the distinctive ligands exhibit different catalytic properties. Ionic ruthenium complex combined with p-cymene ligand may efficiently catalyze the reduction of carbonyl ${ }^{19}$. The ionic ruthenium complex in Figure 2 was conveniently synthesized from the starting material of $\mathrm{RuCl}_{2}\left(\eta^{6}\right.$-p-cymene $)$ by ligand exchange and ionization, and characterized by NMR, EA and HRMS, which also confirmed the complex structure compared with the data reported in the literature ${ }^{24}$. Moreover, HR-MS in Figure 3 provided further information on the structure of the complex. The 574.1003 cation fragment was attributed to the molecular ion of the complex, and the 533.0736 and 145.1256 cation fragments were ascribed to $\left[\mathrm{RuCl}\left(\eta^{6}-\mathrm{p}\right.\right.$-cymene $\left.)\left(\mathrm{PPh}_{3}\right)\right] \mathrm{PF}_{6}$ and $\mathrm{PF}_{6}{ }^{-}$ion, respectively, and a series of fragments from organic ligand in the complex were observed. In addition, the

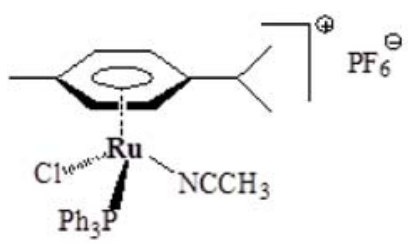

Figure 2. Structure of ionic $[\mathrm{Ru}]$ catalyst

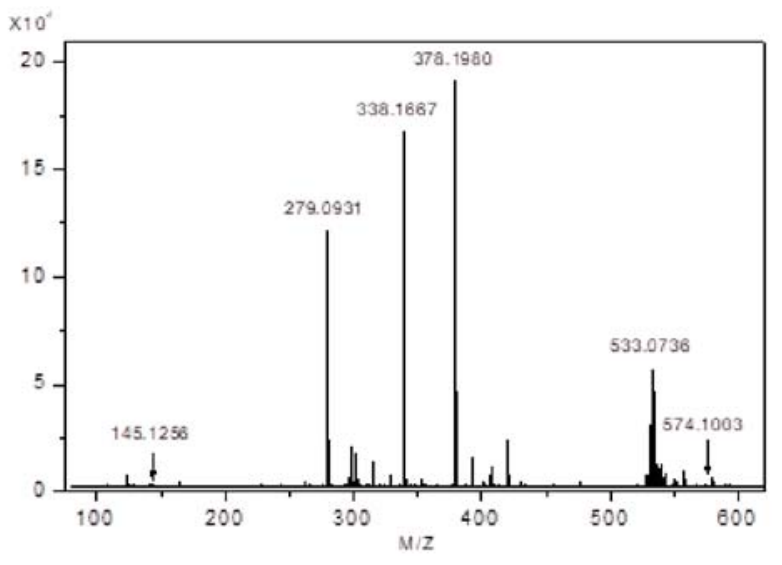

Figure 3. High resolution mass spectrogram of catalyst 
ionic complex of $\left[\mathrm{RuCl}\left(\eta^{6}-\mathrm{p}\right.\right.$-cymene $\left.)\right] \mathrm{PF}_{6}$ was obtained from the $\mathrm{PF}_{6}{ }^{-}$in $\mathrm{AgPF}_{6}$ replacement of $\mathrm{Cl}^{-}$in $\mathrm{RuCl}_{2}\left(\eta^{6}-\mathrm{p}\right.$ cymene)to inconveniently carry out the catalytic reaction and workup, As shown in Figure 2, the representative complex with four different ligands was relatively stable due to the concert of the four ligands to ruthenium, which was significant to catalysis. At the same time, the positive charge on the complex may help the catalyst capture the carbonyl to be reduced, and then anion $\mathrm{PF}_{6}{ }^{-}$as a whole was slightly deviated from the ruthenium center ${ }^{24-25}$. These findings provided the structural basis for the complex catalyst recovery of electric-adsorption after the catalytic transfer hydrogenation of aryl ketones.

\section{Catalytic reactions}

The complex of ionic $[\mathrm{Ru}]$ can efficiently catalyze the transfer hydrogenation of carbonyl. In view of the reported results of the ruthenium complexes for the catalytic transfer hydrogenation of carbonyl ${ }^{26-27}, \mathrm{KOH}$ and isopropanol, which were selected as alkali and hydrogen donor in the reaction system, respectively, the reaction temperature was referred to room temperature and $82^{\circ} \mathrm{C}$, and the reaction time was determined by TLC for the real time tracking. Table 1 shows the obtained results with the phenylethanol product, and it clearly presents that the catalytic reaction to the balance with the increase of the ratio of substrate and catalyst $(\mathrm{S} / \mathrm{C})$, and higher the temperature was, shorter the reaction time was. The optimal reaction conditions were the $\mathrm{S} / \mathrm{C}$ molar ratio of $200,82^{\circ} \mathrm{C}$ of the temperature, and $2 \mathrm{~h}$ of the reaction time, and the corresponding conversion of acetophenone to phenylethanol was $97 \%$. Compared with other ionic $[\mathrm{Ru}]$ complex for the reduction of carbony ${ }^{28}$, the reaction was not required to be performed for long time according to TLC analysis. Thus, it was speculated that the concerted coordination of four different ligands, which were differently capable of steric and electronic effects, to the center metal of Ruthenium played an important role in catalysis. Moreover, for the catalytic reaction, the catalyst was perhaps simple and better in terms of structure and composition for the design or choice.

In order to investigate the substrate scope of the catalyst, especially the influence of electrical difference of the substrate on the catalytic performance, the acetophenone derivatives with methyl or nitro were selected as substrate reactants for the test under the above optimal conditions, and the catalytic results are listed in Table 2 .

Table 1. Reaction optimization for transfer hydrogenation of acetophenone

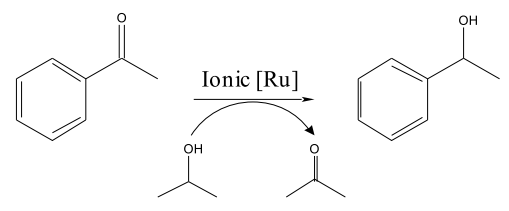

\begin{tabular}{|l|c|c|c|c|}
\hline Entry & $\mathrm{S} / \mathrm{C}[\mathrm{mol}]$ & $\mathrm{T}\left[{ }^{\circ} \mathrm{C}\right]$ & $\mathrm{t}[\mathrm{h}]$ & Conversion [\%] \\
\hline 1 & 50 & 82 & 1 & 98 \\
\hline 2 & 100 & 82 & 1.5 & 95 \\
\hline 3 & 200 & 25 & 2.5 & 92 \\
\hline 4 & 200 & 82 & 1.9 & 97 \\
\hline 5 & 500 & 82 & 3.0 & 90 \\
\hline
\end{tabular}

Reaction conditions: $2.6 \times 10^{-5} \mathrm{~mol}$ catalyst, $5.2 \times 10^{-4} \mathrm{KOH}$, $25 \mathrm{~mL}$ isopropanol, time by TLC and conversion by GC
Table 2. Catalytic transfer hydrogenation of acetophenone derivatives

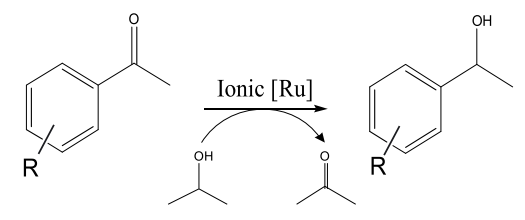

\begin{tabular}{|l|c|c|c|}
\hline Entry & $\mathrm{R}-$ & $\mathrm{t}[\mathrm{h}]$ & Conversion [\%] \\
\hline 1 & $\mathrm{H}$ & 1.9 & 97 \\
\hline 2 & $2-\mathrm{CH}_{3}$ & 2.6 & 89 \\
\hline 3 & $3-\mathrm{CH}_{3}$ & 2.1 & 92 \\
\hline 4 & $4-\mathrm{CH}_{3}$ & 2.4 & 90 \\
\hline 5 & $2-\mathrm{NO}_{2}$ & 1.6 & 98 \\
\hline 6 & $3-\mathrm{NO}_{2}$ & 1.8 & 98 \\
\hline 7 & $4-\mathrm{NO}_{2}$ & 1.5 & $>99$ \\
\hline
\end{tabular}

Reaction conditions: $2.6 \times 10^{-5} \mathrm{~mol}$ catalyst, $5.2 \times 10^{-4} \mathrm{KOH}$, $5.2 \mathrm{mmol}$ acetophenone derivatives, $25 \mathrm{~mL}$ isopropanol, $82^{\circ} \mathrm{C}$, time by TLC and conversion by GC

In addition, the outcomes of both TLC analysis and IR spectra illustrated that the nitro substituent in substrates was not reduced. Obviously, the catalyst indicated the good performance of acetophenone derivatives to the corresponding alcohol compounds; however, the catalytic results were different with acetophenone from methyl or nitro derived from the electrical nature of the group. The substituted position in the acetophenone indicates that the reaction time was also discriminative. By the catalytic reduction of acetophenone as a reference, for the nitro as electron withdrawing group, the catalytic results were better with shorter reaction time, and the catalytic conversions were higher than that of acetophenone, with the conversion of up to $99 \%$ to the acetophenone of $4-\mathrm{NO}_{2}$. While for the methyl as electron-donating group, the catalytic conversion relatively decreased with longer reaction time, and the conversion was only $92 \%$ for the acetophenone of $3-\mathrm{CH}_{3}$. However, here the catalytic efficiency of the ionic [Ru] complex was no less than that of other $\mathrm{Ru}$ catalysts modified by fine ligands ${ }^{29-30}$ for the transfer hydrogenation of aryl ketones. The probability of collision between the catalyst and carbonyl increased, whereas the enhanced interaction between ionic $[\mathrm{Ru}]$ and carbonyl polarization from the electron withdrawing group were positive, on the contrary, the electron-donating group was passive.

The reaction mechanism of the transfer hydrogenation of carbonyl catalyzed by Ruthenium complexes ${ }^{28,31-32}$, which might reasonably describe the process of the catalytic reaction, is discussed here. From the result of the catalyst HR-MS, the acetonitrile ligand in the catalyst was weakly coordinated to ruthenium, thus, it was dissociative from ruthenium, resulting in the coordination unsaturation of the central Ruthenium. In addition, the elimination of chlorine happened by the exchange of K-isopropoxide, simultaneously leading to the formation of Ru-H species with the release of acetone. Under the help of the charge adsorption of ionic ruthenium, quickly the insertion of aryl ketone to $\mathrm{Ru}-\mathrm{H}$ species was in progress. Finally the alcohol metathesis was undergone with the generation of aryl alcohol product and the recovery of original catalyst. The cationic part in the catalyst was involved in the catalytic process, and very 
likely the anionic portion did not directly joined in the catalytic reaction.

\section{Recycling test of catalyst by electro-adsorption}

The used catalyst was ionic and the result of crystal diffraction analysis to similar ionic organometallics ${ }^{\mathbf{2 4}, \mathbf{2 6}}$ revealed that both of cationic and anionic portions were not close together like the dissociation of inorganic compound in water. Thus, both ions can shift in the direction of the field of electricity and several aggregating two electrodes, such as seawater desalination by electric adsorption ${ }^{33}$. In this study, the catalyst recovery was based on the above electric-adsorption principal. In the experiments, we found that ionic [Ru] could not be completely adsorbed once for recovery, Figure 4 shows that the concentration of the ionic $[\mathrm{Ru}]$ in residual liquid after decreased from the high end of range with the increase in number of times of electric-adsorption, and the catalyst concentration was less than $<10^{-5} \mathrm{mmol} / \mathrm{L}$ after 10 times adsorption.

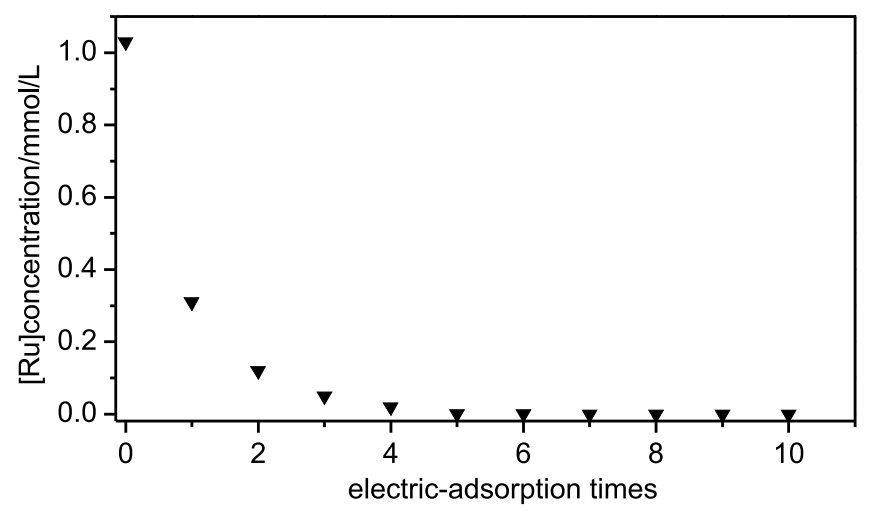

Figure 4. Relationship between electric-adsorption times and concentration of residual catalyst in reacted liquid

Based on the above results, ionic [Ru] recycling test was carried out after collecting the catalyst for 10 times through the electric-adsorption, and the test results are listed in Figure 5 under the optimal conditions. The reusability of the catalyst was good, and the catalytic conversion could still maintain up $90 \%$ after 5 cycles. This indicated that the electrical recovery of the catalyst could not destroy the structure of the catalyst; otherwise the catalytic activity would seriously decrease or even lose. Moreover, the part loss of catalytic activity was related

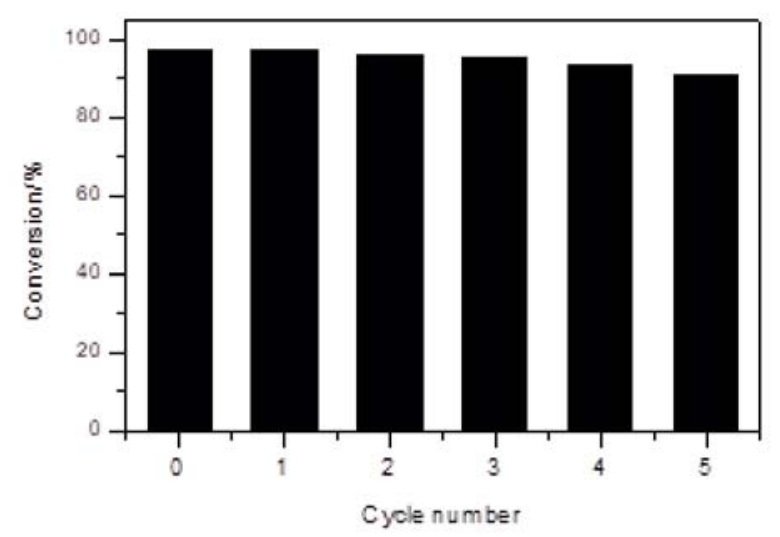

Figure 5. Effect of recycling times of ionic $[\mathrm{Ru}]$ on conversion to the light damage of catalyst besides the loss during the operation due to the probable damage to the active structure by electric-adsorption. However it was kept that the high catalytic performance of the homogeneous catalysis, showing the merit of the easy separation of the heterogeneous catalyst compared with the conventional heterogenization of noble metal catalyst ${ }^{11-13}$.

It was seen that here was the perfect combination the homogeneous catalysis with the heterogeneous one by the ionic $[\mathrm{Ru}]$, and the homogeneous catalyst with the recovery by electric-adsorption exhibited the feature of the high activity and recycling. However, the repeated operation of the electric-adsorption process perhaps resulted in the damage of catalyst, which needs to be improved from the aspects of electrode plate materials and the operation process.

\section{CONCLUSION}

Ionic ruthenium complex containing four different ligands was readily synthesized for the catalytic transfer hydrogenation of aryl ketones. The complex exhibited excellent catalytic performance with $97 \%$ conversion of acetophenone, which was no less than that of other catalysts. The scope of the substrate was wide with $>89 \%$ conversion. The advantages of the ionic ruthenium catalyst include recovery and reuse by electric-adsorption method, which broadened the catalytic approach to heterogenizationin a certain sense. Thus, it may be realized that the high catalytic efficiency in homogeneous catalysis and the easy of the separation of catalysts after heterogeneous catalysis. However, this process still needs further improvement.

\section{ACKNOWLEDGEMENTS}

The subject was sponsored by Qin Lan Project of the Education Department of Jiangsu province in china.

\section{LITERATURE CITED}

1. Chen, F., Wang, T. \& Jiao, N. (2014). Recent advances in transition-metal-catalyzed functionalization of unstrained carbon-carbon bonds. Chem. Rev. 114, 8613-8661. DOI: $10.1021 / \mathrm{cr} 400628 \mathrm{~s}$

2. D’yakonov, V.A., Trapeznikova, O.A., de Meijere, A. \& Dzhemilev, U.M.(2014). Metal complex catalysis in the synthesis of spirocarbocycles. Chem. Rev. 114, 5775-5814. DOI: 10.1021/cr400291c.

3. Margalef, J., Pàmies, O. \& Diéguez, M. (2016). Designing new readily available sugar-based ligands for asymmetric transfer hydrogenation of ketones. In the quest to expand the substrate scope. Tetrahedron Lett. 57, 1301-1308. DOI: 10.1016/j.tetlet.2016.02.022.

4. Zhang, G.Q., Yin, Z.W. \& Tan, J.W. (2016). Cobalt(II)-catalysed transfer hydrogenation of olefins. RSC $A d v$. 6, 22419-22423. DOI: 10.1039/C6RA02021F.

5. Ito, J. \& Nishiyama, H. (2014). Recent topics of transfer hydrogenation. Tetrahedron Lett. 55, 3133-3146. DOI: 10.1016/j. tetlet.2014.03.140.

6. Castellanos-Blanco, N., Arévalo, A. \& García, J.J. (2016). Nickel-catalyzed transfer hydrogenation of ketones using ethanol as a solvent and ahydrogen donor. Dalton Trans. 45,13604-13614. DOI: 10.1039/C6DT02725C.

7. Thangavel, S., Boopathi, S., Mahadevaiah, N., Kolandaivel, P., Pansuriya, P.B. \& Friedrich, H.B. (2016). Catalytic oxidation of primary aromatic alcohols using half sandwichIr(III), 
$\mathrm{Rh}(\mathrm{III})$ and $\mathrm{Ru}(\mathrm{II})$ complexes: A practical and theoretical study. J. Mol. Catal. A: Chem. 423,160-171. DOI: 10.1016/j. molcata.2016.06.017.

8. Saadati, F., Khani, N., Rahmani, M. \& Piri, F. (2016). Preparation and characterization of nanosized copper (II) oxide embedded in hyper-cross-linked polystyrene: Highly efficient catalyst for aqueous-phase oxidation of aldehydes to carboxylic acids. Catal. Commun. 79, 26-30. DOI: 10.1016/j. catcom.2015.12.016.

9. Ruiz, S., Villuendas, P. \& Urriolabeitia, E.P. (2016). Rucatalysed $\mathrm{C}-\mathrm{H}$ functionalisations as a tool for selective organic synthesis. Tetrahedron Lett. 57, 3413-3432. DOI: 10.1016/j. tetlet.2016.06.117.

10. Pappas, I. \& Chirik, P.J. (2016). Catalytic Proton Coupled Electron Transfer from Metal Hydrides to Titanocene Amides, Hydrazides and Imides: Determination of Thermodynamic Parameters Relevant to Nitrogen Fixation. J. Am. Chem. Soc. 138, 13379-13389. DOI: 10.1021/jacs.6b08009.

11. Schlogl, R. (2015). Heterogeneous catalysis [J]. Angew. Chem. Int. Ed. 54, 3465-3520. DOI: 10.1002/anie.201410738.

12. Nishimura, S. \& Ebitani, K. (2016). Recent advances in heterogeneous catalysis with controlled nanostructured precious monometals. Chem. Cat. Chem. 8, 2303-2316. DOI: 10.1002/ cctc. 201600309.

13. Corma, A., Garcı'a, H. \& Xamena, F.X.L. (2010). Engineering metal organic frameworks for heterogeneous catalysis. Chem. Rev. 110, 4606-4655. DOI: 10.1021/cr9003924.

14. Polshettiwar, V., Luque, R., Fihri, A., Zhu, H., Bouhrara, M. \& Basset, J.M. (2011). Magnetically recoverable nanocatalysts. Chem.Rev. 111, 3036-3075. DOI: 10.1021/cr100230z.

15. Fernandez, F.E., Puerta, M.C. \& Valerga, P. (2011). Half-sandwich Ruthenium(II) picolyl-NHC complexes:synthesis, characterization, and catalytic activity in transfer hydrogenation reactions. Organometallics 30, 5793-5802. DOI: 10.1021/ om200665f

16. Pan, S.G., Matsuo, Y., Endo, K. \& Shibata, T. (2012). Cationic iridium-catalyzed enantioselective activation of secondary $\mathrm{sp}^{3} \mathrm{C}-\mathrm{H}$ bondadjacent to nitrogen atom. Tetrahedron 68, 9009-9015. DOI: 10.1016/j.tet.2012.08.071.

17. Verendel, J.J., Pàmies, O., Diéguez, M. \& Andersson, P.G. (2014). Asymmetric hydrogenation of olefins using chiral crabtree-typecatalysts: scope and limitations. Chem. Rev. 114, 2130-2169. DOI: $10.1021 / \mathrm{cr} 400037 \mathrm{u}$.

18. Perez, M., Elangovan, S., Sannenberg, A., Junge, K. \& Beller, M. (2016). Molecularly defined manganese pincer complexes for selective transfer hydrogenation of ketones. Chem. Sus. Chem. 9, 1-5. DOI: 10.1002/cssc.201601057.

19. Kanchanadevi, A., Ramesh, R. \& Semeril, D. (2016). Efficient and recyclable $\mathrm{Ru}(\mathrm{II})$ arene thioamide catalysts for transfer hydrogenation of ketones: Influence of substituent on catalytic outcome. J. Organomet. Chem. 808, 68-77. DOI: 10.1016/j.jorganchem.2016.02.016.

20. Hodson, E. \& Simpson, S.J. (2004). Synthesis and characterisation of $\left[\left(\eta^{6}\right.\right.$-cymene $\left.) \mathrm{Ru}(\mathrm{L}) \mathrm{X}_{2}\right]$ compounds:single crystal $\mathrm{X}$-ray structure of $\left[\left(\eta^{6}\right.\right.$-cymene $\left.) \mathrm{Ru}\left(\mathrm{P}\{\mathrm{OPh}\}_{3}\right) \mathrm{Cl}_{2}\right]$ at $203 \mathrm{~K}$. Polyhedron 23, 2695-2707. DOI: 10.1016/J.POLY.2004.06.016.

21. Hanif, M., Nazarov, A.A. \& Hartinger, C.G. (2012). Synthesis of $\left[\mathrm{Ru}^{\mathrm{II}}\left(\eta^{6}\right.\right.$-p-cymene $\left.)\left(\mathrm{PPh}_{3}\right)(\mathrm{L}) \mathrm{Cl}\right] \mathrm{PF}_{6}$ complexes with carbohydrate-derived phosphites, imidazole or indazole co-ligands. Inorg. Chim. Acta 380, 211-215. DOI:10.1016/j. ica.2011.10.007.

22. Hu,C.Z., Liu, F.Y., Lan, H.C. \& Liu, H.J. (2015). Preparation of a manganese dioxide/carbon fiber electrode for electrosorptive removal of copper ions from water. J. Coll. Inter. Sci. 446, 359-365. DOI: 10.1016/J.JCIS.2014.12.051.

23. Amin. A.S. (2002). Simple and selective spectrophotometric determination ofruthenium after solid phase extraction with somequinoxaline dyes into microcrystalline $p$-dichlorobenzene. Spectrochim. Acta Part. A. 58, 1831-1837. DOI: 10.1016/ S1386-1425(01)00681-3.
24. Chaplin, A.B., Fellay, C., Laurenczy, G. \& Dyson, P.J. (2007).Mechanistic Studies on the Formation of $\eta^{2}$ Diphosphine $\left(\eta^{6}-p\right.$-cymene)ruthenium(II) Compounds. Organometallics 26, 586-593. DOI: 10.1021/om060752n.

25. Gichumbi, J.M., Friedrich, H.B. \& Omondi, B. (2016). Synthesis and characterization of half-sandwich ruthenium complexes with $\mathrm{N}$-alkyl pyridyl-imine ligands and their application in transfer hydrogenation of ketones. Transit. Met. Chem. 41, 867-877. DOI: 10.1007/s11243-016-0089-5.

26. Lin, T.H., Das, K., Datta, A., Leu, W.J., Hsiao, H.C., Lin, C.H., Guh, J.H., Huang, J.H. (2016). Synthesis and characterization of ruthenium compounds incorporating keto-amine ligands. The applications of catalytic transfer hydrogenation and cancer cell inhibition. J. Organomet. Chem. 807, 22-28. DOI: 10.1016/j.jorganchem.2016.01.029.

27. Chai, H.N., Liu, T.T., Wang, Q.F. \& Yu, Z.K. (2015). Substituent effect on the catalytic activity of Ruthenium(II) complexes bearing a pyridyl-supported pyrazolyl-imidazolyl ligandfor transfer hydrogenation of ketones. Organometallics, 34, 5278-5284. DOI: 10.1021/acs.organomet.5b00727.

28. Mai, V.H. \& Nikonov, G.I. (2016). Transfer Hydrogenation of Nitriles, Olefins, and N-Heterocycles Catalyzed by an N-Heterocyclic Carbene-Supported Half-Sandwich Complex of Ruthenium. Organometallics 35, 943-949. DOI: 10.1021/ acs.organomet.5b00967.

29. Yamamura, T., Nakane, S., Nomura, Y., Tanaka, S. \& Kitamura, M. (2016). Development of an axially chiral $\mathrm{sp}^{3} \mathrm{P} /$ $\mathrm{sp}^{3} \mathrm{NH} / \mathrm{sp}^{2} \mathrm{~N}$-combined lineartridentate liganddfac-selective formation of $\mathrm{Ru}(\mathrm{II})$ complexes and application to ketone hydrogenation. Tetrahedron 72, 3781-3789. DOI: 10.1016/j. tet.2016.02.007.

30. Paul, B., Chakrabarti \& Kundu, K.S. (2106). Optimum bifunctionality in a 2-(2-pyridyl-2-ol)-1,10-phenanthroline based ruthenium complexfor transfer hydrogenation of ketones and nitriles:impact of the number of 2-hydroxypyridinefragments. Dalton Trans. 45, 11162-11171. DOI: 10.1039/C6DT01961G.

31. Rath, R.K., Nethaji, M. \& Chakravarthy, A.R. (2001). Transfer hydrogenation of acetophenone promoted by (arene) ruthenium(II) reduced Schiff base complexes: an X-ray structure of $\left[\left(\eta^{6}\right.\right.$-p-cymene $) \mathrm{RuCl}\left(\mathrm{OC}_{6} \mathrm{H}_{4}-2-\mathrm{CH}_{2} \mathrm{NHC}_{6} \mathrm{H}_{4}\right.$-p-Me $\left.)\right]$. Polyhedron 20, 2735-2739. DOI: 10.1016/S0277-5387(01)00894-4.

32. Samec, J.S.M., Backvall, J.E., Andersson, P.G. \& Brandt, P. (2006). Mechanistic aspects of transition metal-catalyzed hydrogen transfer reactions. Chem. Soc. Rev. 35, 237-248. DOI: 10.1039/B515269K.

33. Wang, G., Qian, B.Q., Dong, Q., Yang, J.Y., Zhao, Z.B. \& Qiu, J.S. (2013). Highly mesoporous activated carbon electrode for capacitive deionization. Sep. Purif. Technol. 103, 216-221. DOI:10.1016/j.seppur.2012.10.041. 